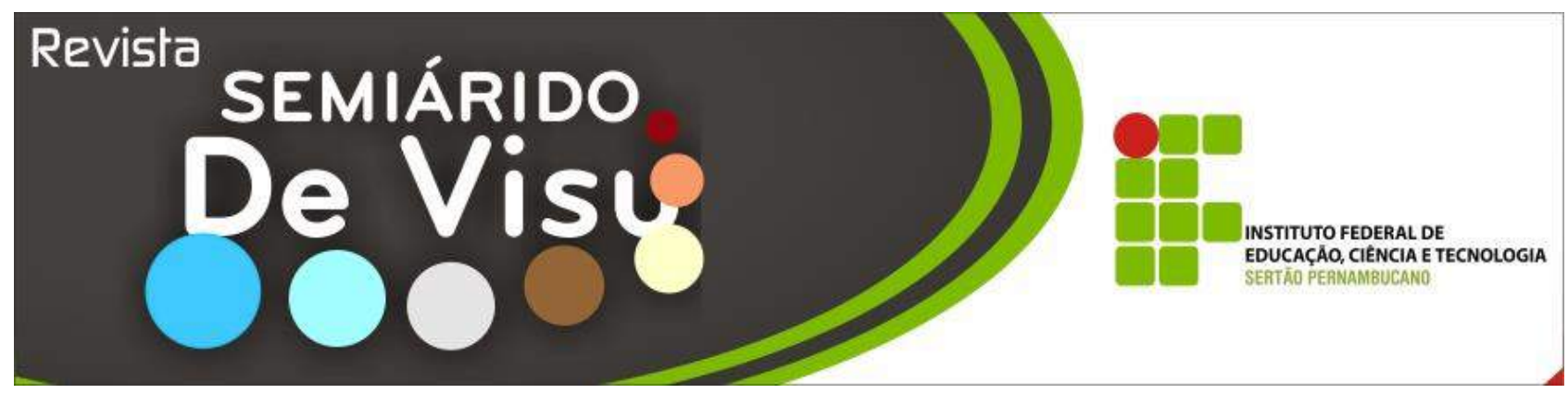

\title{
Avaliação e monitoramento da condutividade elétrica das águas de poços utilizados para a irrigação na região de Salgueiro-PE
}

\author{
Raquel Ferreira dos Santos ${ }^{1}$, Eriverton da Silva Rodrigues ${ }^{2}$, Adriana de Carvalho Figueiredo ${ }^{3}$, Janaílson Cícero da \\ Silva $^{4}$ \\ 1,2,3,4 Instituto Federal de Educação, Ciência e Tecnologia Sertão Pernambucano - Campus Salgueiro. Rodovia Luiz Gonzaga (BR \\ 232), KM 508, Zona Rural - Salgueiro - PE - Brasil. CEP 56000-000, Telefone: (87) 3421-0050/ E-mail: ${ }^{1}$ ruuth.santos@ bol.com.br; \\ ${ }^{2}$ eriverton.rodrigues@ifsertao-pe.edu.br; ${ }^{3}$ adriana.figueiredo@ifsertao-pe.edu.br; ${ }^{4}$ janailsoncs.1995@gmail.com
}

\begin{abstract}
RESUMO: O município de Salgueiro encontra-se localizado em uma região semiárida do estado de Pernambuco, que é caracterizada por apresentar chuvas com distribuição irregular temporal e espacial. Nessa região, a agricultura irrigada surge como alternativa para a sustentabilidade econômica da atividade agrícola. A agricultura é uma das principais atividades econômicas do município. Os principais produtos agrícolas produzidos na região são: cebola, tomate, algodão herbáceo, milho, banana, feijão, arroz e manga. O problema da salinidade em áreas irrigadas se agrava quando o balanço de sais revela maior entrada que saída, promovendo acréscimo da concentração salina na área considerada, condições em que a água de irrigação, além de contribuir para o aumento da concentração salina pode, também, provocar a elevação do lençol freático que, através de ascensão capilar, passa a fornecer água e sais à zona radicular. Dessa forma, este trabalho objetiva avaliar e monitorar a salinidade da água de poços utilizada para fins de irrigação no município de Salgueiro-PE, através da análise da condutividade elétrica. Além disso, o projeto também está sendo aplicado nas comunidades rurais da região, onde o agricultor tem de uma forma simples, conhecimento sobre a salinidade da água dos poços que são utilizadas, principalmente, nas plantações de subsistência.
\end{abstract}

Palavras-chaves: Região Semiárida, Agricultura, Salinidade.

\section{Assessment and monitoring electric of conductivity well water used for irrigation in Salgueiro-PE region}

\begin{abstract}
The municipality of Salgueiro is located in a semi-arid region of the state of Pernambuco, which is characterized by rainfall with irregular temporal and spatial distribution. In this region, irrigated agriculture appears as an alternative for the economic sustainability of agricultural activity. Agriculture is one of the main economic activities of the municipality. The main agricultural products produced in the region are: onion, tomato, herbaceous cotton, corn, banana, beans, rice and mango. The problem of salinity in irrigated areas is aggravated when the salt balance reveals a higher entrance than exit, promoting an increase of the saline concentration in the area under consideration, conditions in which the irrigation water, besides contributing to the increase of the saline concentration, Provoke the elevation of the water table that, through ascending capillary, starts to supply water and salts to the root zone. Thus, this work aims to evaluate and monitor the salinity of well water used for irrigation purposes in the city of Salgueiro-PE, through the analysis of the electrical conductivity. In addition, the project is also being applied in the rural communities of the region, where the farmer has a simple knowledge about the salinity of the wells that are mainly used in subsistence plantations.
\end{abstract}

Keywords: Semiarid region, Agriculture, Salinity. 


\section{Introdução}

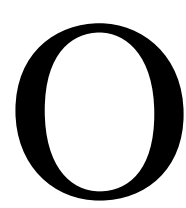

município de Salgueiro está localizado no semiárido nordestino, especificamente na mesorregião Sertão e na Microrregião Médio Capibaribe do Estado de Pernambuco, limitando-se a norte com Estado do Ceará, a sul com Belém do São Francisco, a leste com Verdejante, Mirandiba e Carnaubeira Penha, e a oeste com Cabrobó, Terra Nova, Serrita e Cedro (CPRM, 2005). O clima na região é semiárido com temperatura média anual de $30^{\circ} \mathrm{C}$ e precipitação pluviométrica de 630 $\mathrm{mm} / \mathrm{ano}$, além disso, o período chuvoso se inicia em novembro com término em abril. A região também é caracterizada por baixa pluviosidade, graves problemas de abastecimento de água potável na zona rural e a precipitação média anual é de $431,8 \mathrm{~mm}$. Em função das características climáticas e geológicas da região semiárida (de origem sedimentar), a água subterrânea constitui importante forma de reserva hídrica (JÚNIOR et al, 2006).

A qualidade da água, do ponto de vista agrícola, é um termo que se utiliza para indicar a conveniência ou limitação de seu uso para fins de irrigação. Entretanto, a determinação favorável ou contrária da utilização de água para fins de irrigação requer ter presentes às condições de caráter químico que apresenta a água no momento da análise, como também as características físico-químicas dos solos onde será aplicada, bem como a suscetibilidade e/ou resistência das plantas ou cultivos que serão irrigados. (CARNEIRO, 2012)

A agricultura é uma das principais atividades econômicas do município. Os principais produtos agrícolas produzidos na região são: cebola, tomate, algodão herbáceo, milho, banana, feijão, arroz e manga.

Dados do CPRM do ano de 2005 indicam que o município apresenta 143 poços tubulares registrados, desse total $15 \%$ é destinado à prática de agricultura irrigada .

Dessa forma, a pesquisa objetivou realizar estudo da salinidade das águas dos poços utilizados para irrigação na região do sertão central pernambucano, por meio da condutividade elétrica (CE) obtida através de um experimento alternativo e simples.

\section{Material e métodos}

As áreas de estudo estão localizadas na zona rural do município de Salgueiro-PE. Inicialmente foram realizadas visitas de campo, para a escolha das propriedades que utilizam água de poços para irrigação de culturas agrícolas (Figura 1). Sendo selecionada três propriedades localizadas nas comunidades de Quixaba, Pau Ferro e no IF-SERTÃO PE.

Figura 1: Sistema de irrigação utilizando a água de um dos poços.

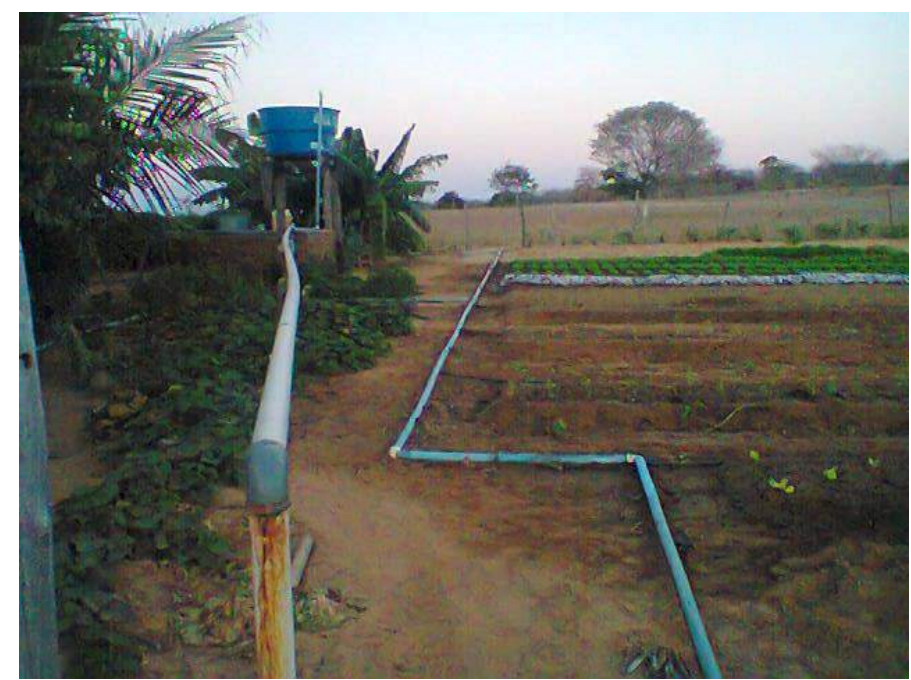

Fonte: Próprio Autor. 
Foi realizado o cadastramento dos poços e aplicado um questionário junto aos agricultores. As amostras foram coletadas em recipientes plásticos estéreis, sendo transportados em caixa térmica contendo gelo, armazenado em refrigerador e conduzidos ao Laboratório de Física do IF SERTÃO PE Campus Salgueiro, onde foram realizadas as leituras dos dados de CE (Figura 2).

Figura 2: Bolsista realizando análises.

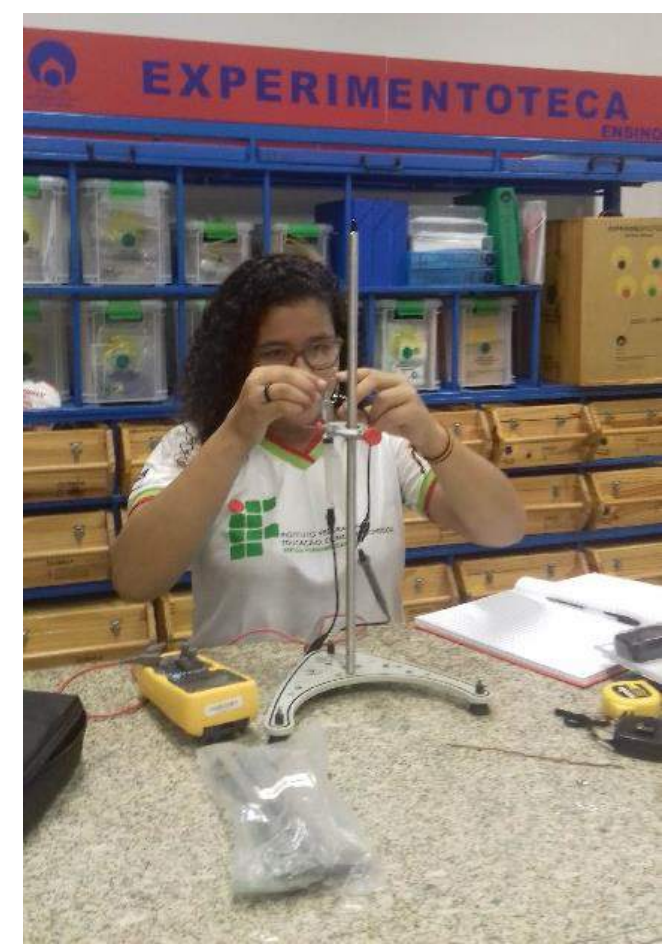

Fonte: Próprio Autor.

Foram realizados testes da $\mathrm{CE}$ da água dos poços através de uma experiência simples que envolve conceitos científicos de física e química. Os materiais utilizados foram: recipiente, multímetro, fios elétricos com crocodilos, dois eletrodos e água a ser testada. $\mathrm{O}$ equipamento de medição é alternativo, de simples manuseio e a leitura dos dados é indireta. Utilizando-se um multímetro realizouse a leitura dos dados de resistência elétrica que passaram por ajustes teóricos a fim de obter os valores de CE. Em seguida, realizou-se a sistematização dos dados buscando analisar o comportamento da salinidade das águas dos poços.

\section{Resultados e discussão}

O conhecimento da qualidade da água subterrânea relativo à concentração salina e de como ela está espacialmente distribuída, é necessário ao planejamento da exploração e ao manejo das águas do aquífero, a fim de garantir sua sustentabilidade e prevenir a degradação dos recursos hídricos (ANDRADE et al., 2012).

Com base nos dados iniciais obtidos no experimento percebemos que as amostras de alguns poços apresentaram salinidade acima de 250 micromhos/cm de CE e outras ficaram abaixo deste valor, sendo propicias para irrigação de certas culturas de subsistência de acordo com a Tabela 1. 
Tabela 1. Valores mensais de CE para os poços analisados

\begin{tabular}{cccc}
\hline \multirow{2}{*}{ Poço } & \multicolumn{3}{c}{ Condutividade elétrica em micromhos.cm } \\
\cline { 2 - 4 } & $\mathbf{1}^{\mathbf{0}}$ Mês & $\mathbf{2}^{\mathbf{0}}$ Mês & $\mathbf{3}^{\mathbf{0}}$ Mês \\
& $($ nov/15) & $(\mathbf{d e z} / \mathbf{1 5})$ & $(\mathbf{j a n} / \mathbf{1 6})$ \\
\hline $\mathbf{1}$ & 152,92 & 194,60 & 251,96 \\
$\mathbf{2}$ & 264,92 & 272,60 & 188,96 \\
$\mathbf{3}$ & 147,34 & 156,08 & 187,13 \\
\hline
\end{tabular}

Fonte: Pesquisa direta.

O problema da salinidade em áreas irrigadas se agrava quando o balanço de sais revela maior entrada que saída, promovendo acréscimo da concentração salina na área considerada, condições em que a água de irrigação, além de contribuir para o aumento da concentração salina pode, também, provocar a elevação do lençol freático que, através de ascensão capilar, passa a fornecer água e sais à zona radicular (SILVA et al., 2008).

De acordo com a classificação da água baseada nos valores de CE (CORDEIRO, 2001), verificou-se que no primeiro e segundo mês do Poço 1, e terceiro mês do Poço 2, a água analisada pode ser usada para irrigação na maior parte dos cultivos em quase todos os tipos de solo, com pouca probabilidade de desenvolver problemas de salinidade.

No primeiro e segundo mês do Poço 2, e terceiro mês do Poço 1, a água analisada pode ser usada sempre que houver um grau moderado de lixiviação. Neste caso, plantas com moderada tolerância aos sais podem ser cultivadas, em muitos casos, sem necessidade de práticas especiais de controle da salinidade. Finalmente, nos três meses referentes ao Poço 3 os resultados mostraram que a água analisada pode ser usada para irrigação na maior parte dos cultivos em quase todos os tipos de solo, com pouca probabilidade de desenvolver problemas de salinidade.

O comportamento da salinidade dos poços, durante os meses de monitoramento, pode ser observado no Gráfico 1. Verifica-se que em alguns meses todos os poços apresentaram qualidade de água propícia para a irrigação de diversos cultivos, entretanto, existem situações que requerem atenção, necessitando de uma investigação relacionada a lixiviação de sais, assim como verificar a relação da variação mensal da salinidade da água para irrigação com a precipitação nas localidades estudadas. Dessa maneira, ressalta-se a importância do estudo, visto que na região em que foi feita a pesquisa o cultivo é feito com plantações que sofrem prejuízos quando se tem elevada concentração salina, como por exemplo, o maracujazeiro.

Gráfico 1: Representação da distribuição mensal dos valores de CE.

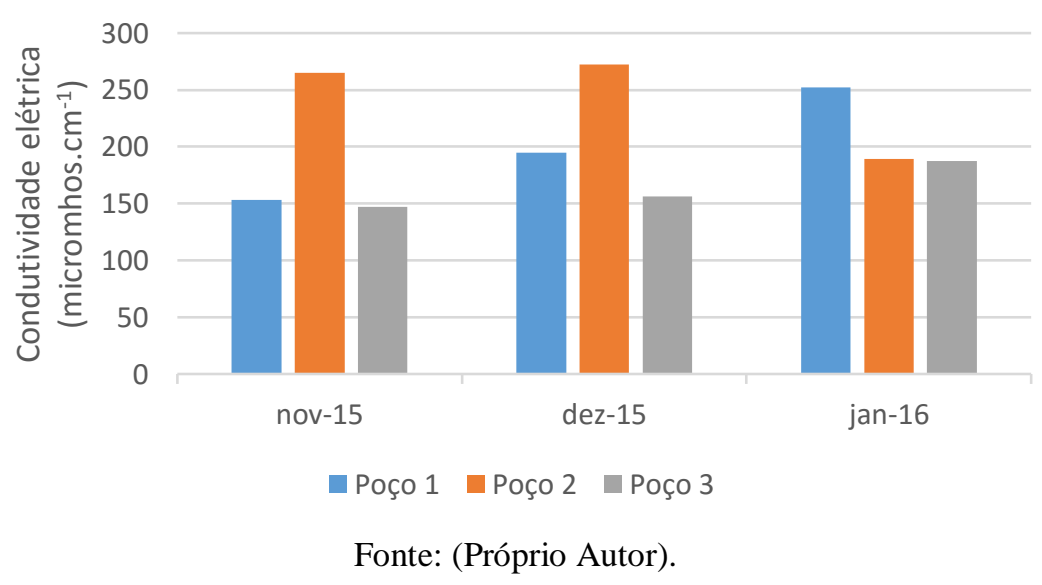


Um dos aspectos mais relevantes, no tocante ao sucesso da irrigação como prática agrícola, diz respeito à qualidade da água de irrigação, principalmente em casos de regiões áridas e semiáridas, nas quais pode ocorrer um aumento na concentração de sais, degradando os solos e, consequentemente, inviabilizando a produção (PESSOA et al., 2012). Assim, esperase um bom aproveitamento da pesquisa nas comunidades rurais da região de Salgueiro, que poderão fazer uso do modelo experimental proposto como uma forma simples e barata para obter o conhecimento necessário sobre a salinidade da água utilizada na irrigação.

Os dados de acompanhamento da salinidade foram apresentados mensalmente aos agricultores para conhecimento da qualidade da água utilizada para a irrigação em seus plantios. Entretanto, diante do comportamento dos valores de salinidade observados (Gráfico 1), verifica-se a necessidade da continuidade do monitoramento para que se reconheça a qualidade da água ao longo do tempo.

\section{Conclusões}

A determinação da CE, por meio de experimento alternativo, apresentou variações nos valores mensais dos poços 1 e 2 . No Poço 3 observou-se valores de baixa salinidade, permanecendo abaixo do valor de referência com menos de 250 microhoms.cm ${ }^{-1}$.

$\mathrm{O}$ experimento alternativo de medição mostrou-se eficiente na determinação da CE das águas dos poços analisados.

Os resultados corroboram para a necessidade do monitoramento da salinidade das águas de poços utilizadas para irrigação na zona rural do município de Salgueiro-PE.

\section{Referências}

ANDRADE, T.S.; MONTENEGRO, S.M.G.L., MONTENEGRO, A.A.A.; RODRIGUES, D.F.B. Variabilidade espaço-temporal da condutividade elétrica da água subterrânea na região semiárida de Pernambuco. Revista. Brasileira de. Engenharia. Agrícola e.
Ambiental. Campina Grande, v.16, n.5, p.496504, 2012.

CARNEIRO, M. F. C., INGÁ, M. A. M., FILHO, H. A. S., SANTOS, E. V. M., ROLIM, H. O. R., CHAVES, J. R. Avaliação da Qualidade da Água para Irrigação no Perímetro Irrigado Jaguaribe Apodi no Município de Limoeiro do Norte-CE. Congresso Norte Nordeste de Pesquisa e Inovação, Palmas TO, 2012.

CORDEIRO, G. G. Qualidade de água para fins de irrigação. (Conceitos básicos e práticas). Embrapa Semiárido, Petrolina, PE, 2001.

CPRM - Serviço Geológico do Brasil. Projeto cadastro de fontes de abastecimento por água subterrânea. Diagnóstico do município de Salgueiro, estado de Pernambuco / Organizado [por] João de Castro Mascarenhas, Breno Augusto Beltrão, Luiz Carlos de Souza Junior, Manoel Julio da Trindade G. Galvão, Simeones Neri Pereira, Jorge Luiz Fortunato de Miranda. Recife: CPRM/PRODEEM, 2005.

JÚNIOR, A. S. A., SILVA, Ê. F. F., BASTOS, E. A., MELO, F. B. e LEAL, C. M. Uso e qualidade da água subterrânea para irrigação no Semiárido piauiense. Revista Brasileira de Engenharia Agrícola e Ambiental. Campina Grande, v.10, n.4, p.873-880, 2006.

PESSOA, L.G.M.; FREIRE, M. B. G. S.; FREIRE, F. J. F.; MENEZES, D. Crescimento de cebola irrigada com águas salinas em solos do semiárido de Pernambuco. Revista Brasileira de Ciências Agrárias. Recife, v.7, n.3, p.527-534, 2012.

SILVA, M. O., FREIRE, M. B. G. S., MENDES, A. M. S., FREIRE, F. J., SOUSA, C. E. S. e GÓES, G. B. Crescimento de meloeiro e acúmulo de nutrientes na planta sob irrigação com águas salinas. Revista Brasileira de Engenharia Agrícola e Ambiental. Campina Grande, v.12, n.6, p.593-605, 2008. 